\title{
JUAN TÉLLEZ
}

\author{
XAVIER MOYSSÉN \\ A Fausto Ramirez Rojas
}

Un pintor del cual no se habla hoy en día, no obstante los méritos de su obra, y el hecho de que ésta llamó la atención de la crítica en cuantas ocasiones fue mostrada, mereciendo incluso algún premio en Europa, tal es el caso de Juan Téllez, a quien el olvido no hundió del todo, gracias a las referencias que sobre él hicieron tanto Justino Fernández como Abelardo Carrillo y Gariel.1.

Juan Téllez nació en Sevilla el 24 de junio de 1879. Llegó a México cuando contaba con cinco años de edad. Aquí mismo terminó sus días, enajenado mentalmente, el 22 de abril de 1930. Fue hijo de Pedro Téllez Toledo y de Celedonia Hellín y Muela; mas antes de continuar, éste es el momento oportuno para hacer una aclaración respecto a sus apelativos. Según costumbre él debió llamarse Juan Téllez Hellín y no con los apellidos que correspondían a su padre; en sus pinturas firmaba solamente: J. Téllez; sin embargo, se le conoció por la prensa diaria y por los trabajos de los críticos de arte, como Juan Téllez Toledo, lo que aceptó Justino Fernández al ocuparse del artista, mas no así Abelardo Carrillo y Gariel, quien escribió su nombre en la forma establecida, es decir como Téllez Hellín. En el presente trabajo se ha optado por nombrarle en la forma que él adoptó para firmar sus telas: Juan Téllez.

Hacia fines del siglo xIx y probablemente muy joven aún, ingresó a la antigua Academia de San Carlos para estudiar pintura, mas tuvo oportunidad de hacerlo también en España; según Justino Fernández, en 1899 se fue a Sevilla, "En donde fue discípulo de José García Ramos". Durante los años pasados en España Juan Téllez debió entusiasmarse ante los cuadros de los maestros del Siglo de Oro, por las

1 Justino Fernández se ocupó de él, en 1937, en su libro El arte moderno en México. Breve historia siglos xix y xx, p. 189, y años más tarde, en 1967, en su obra El arte del siglo xix en México, p. 166. Abelardo Carrillo y Gariel publicó una interesante ficha sobre Téllez Toledo en: Las galerias de San Carlos, p. 40. Consúltese Enciclopedia Mexicana de Arte, núm. 6, México, 1950. Aprovechando las noticias que consigna Carrillo y Gariel, se incluyó al artista en la Enciclopedia del Arte en América, Buenos Aires, 1968, t. III, sin número de paginación.

2 Op. cit., p. 189. 
repercusiones que hay en su obra; mas también se interesó por lo que hacían los pintores del momento, como Joaquín Sorolla, Darío de Regoyos, Daniel Vázquez Díaz y sobre todo debió identificarse con Ignacio Zuloaga y el espiritu de su arte; se asegura, incluso, que entre ambos pintores se estableció una estrecha amistad, lo que parece corroborar la obra de Téllez. En 1903 regresó a México, según un breve comentario de Diego Rivera. ${ }^{3}$

José Juan Tablada, en las diferentes ocasiones en las que se ocupó de los trabajos de Juan Téllez, lo hizo con un especial interés sin parar en mientes al elogiarle y defenderle de un ambiente que seguramente le era hostil. Es posible que el crítico viera en él una posibilidad de renovación de la pintura mexicana de principios de siglo; así pudo escribir lo siguiente:

Como un bólido que, sin anunciarse (así) cayó Juan Téllez en nuestro medio artístico... En derredor de la obra del joven pintor, entre los comentarios adversos, pueden distinguirse, dos especies de antagonistas: los que por infima capacidad de espíritu, no pueden comprenderlo, y los que por interés propio, por instinto de conservación, no quieren comprenderlo... Los que no quieren comprender la obra admirable de Téllez, se defienden, porque admitir esa obra de arte verdadero, sería negar la obscura obra de engaño, de impo. tencia y falsedad, con que ellas suplantan y profanan el nombre de Artista. ${ }^{4}$

Tablada ilustró su crítica de manera propositiva, con el cuadro $L a$ labor (figura 2) sin duda uno de los más significativos y en el que se muestran los méritos de Téllez, razón de la esperanza de cambio que veía en ế. Resaltó también los éxitos logrados por el artistá en Eūropa: "Téllez fue admitido, escribió, en el Salón del Campo de Marte, de París, y obtuvo la medalla y el premio de 1,000 pesetas en la exposición de Madrid."'s

En 1905 Juan Téllez abandonó nuevamente el país, en esta ocasión con destino a la Ciudad Luz, gracias a una pensión que le otorgó la academia. Tres años más tarde retornó con la satisfacción de los que

3 Recogido por Loló de la Torriente en Memoria y razón de Diego Rivera, México, 1959, t I, p. 251.

4 José Juan Tablada, "Pintores nuevos. Juan Téllez", Revista Moderna de Méxi. co, México, enero de 1905, pp. 244-46.

s Ibid. 
han alcanzado el triunfo, pues según Alfonso Cravioto, otro de los críticos de la época, la prensa parisiense se ocupó de él con cierta atención; Cravioto anotó, asimismo, que en París aprendió a grabar, y que había realizado ya "Una colección de aguas fuertes... sólidas, amplias y harmoniosas en el misterio de sus aguas tintas". ${ }^{6}$ Sin embargo, lo más importante para el crítico era el hecho que el pintor regresaba,

consciente por completo, dueño de sí y de su pincel, ya sin influencias extrañas pronunciadas, todo sinceridad y todo entusiasmo, dispuesto a realizar obras de ambiente y tipos mexicanos y a contribuir, como es de esperarse, a la decoración de nuestro Teatro $\mathrm{Na}$ cional..." 7

Esto último debe verse como un antecedente de lo que años más tarde, con el mismo fin, se ofrecería a Saturnino Herrán.

Hacia fines de 1906 se efectuó en la Academia de Bellas Artes una exposición con obras enviadas por los artistas pensionados en Europa. Entre los escultores se encontraban los siguientes: Fidencio Nava, Enrique Guerra y Arnulfo Domínguez Bello. El grupo de pintores era de primera; lo constituían Alberto Fuster, Alfredo Ramos Martínez, Julio Ruelas, Roberto Montenegro, Francisco Goitia, Leandro Izaguirre, Francisco de la Torre y Juan Téllez; también estuvo presente Diego Rivera "No pensionado aún, pero acreedor a ello a más de un título, figuró con varios paisajes; un patio de casa abandonada, dos paisajes de Ixtacalco una bella impresión de noche y un retrato lleno de carácter". 8

La reseña de la exposición escrita por José Juan Tablada bajo el seudónimo de Okusai, no oculta la inconformidad del crítico ante lo que se producía en la academia, "... Ese plantei donde fiota una atmósfera de tedio, donde las obras de la Escuela de Clavé nada dicen y nada sugieren..."; así se explica el entusiasmo con el que se refirió a las proposiciones pictóricas que mostraban los artistas pensionados. Para Juan Téllez no tuvo sino elogiosas palabras...

6 Los comentarios de Alfonso Cravioto se publicaron en la Revista Moderna de México, México, noviembre de 1907, pp. 182-83. Aunque los comentarios aparecieron firmados con las iniciales A.C., no hay duda de que él fue el autor.

7 Ibid.

8 Véase: "Arte y Artistas". "Los Pensionados Mexicanos en Europa", en El Mundo Ilustrado, Año xIV, número 1 , sin numeración de páginas, México, enero $1^{\circ}$ de 1907. El artículo está firmado por Okusai, que, como se sabe, es uno de los seu. dónimos de José Juan Tablada. 
“...presentó tres retratos y un estudio. De aquéllos, el retrato del padre y de una hermana del artista son interesantísimos. No hay rebuscamiento de técnica, ni alarde de procedimiento: sino una simplicidad sintética y una bella sinceridad. No hay efectismos de color, ni iluminaciones de estudio, ni osadías de plein air sino una severa gama armónica y una exquisita tonalidad. Además los retratos de Téllez tienen gran carácter y fuerte expresión. Y hay un no sé qué anímico, influencia espiritual, efluvio del yo interno que presta a esas obras un misterio vital. Como el inmenso Whisler, Téllez tiende a pintar no al individuo, sino a su "Segunda realidad".

En junio de 1908 Juan Téllez retornó a México El Diario Ilustrado dio noticia de ello y el anónimo autor del artículo que se le dedicó hizo comentarios de las obras que a su juicio, eran de importancia en el trabajo del pintor. Ante la pregunta que se formuló a sí mismo, sobre "¿cuál es el carácter dominante en Téllez Toledo?", no demoró en contestar, que era el color. Siguiendo un criterio establecido señaló, en primer lugar, el cuadro La labor, el mismo que interesara a Tablada. Como pintura notable anotó también, la del Interior de una Iglesia y, por supuesto, varios retratos, entre ellos uno de Rubén Dario, otro de Luis. G. Urbina y el de Una novia, que le mereció comentarios "Por las tonalidades blancas del vestido de la hermosa mujer en un fondo verde".

$\mathrm{El}$ autor del escrito estaba informado en materia de arte, pues se dio cuenta de la presencia de Ignacio Zuloaga en la obra de Téllez y al respecto escribió:

Aun cuando el pintor nos ha manifestado en varias ocasiones que no es el estilo de Zuloaga el que campea en varios de sus cuadros, sino que es el estilo "De todo lo que es de España", notamos, sin embargo, una influencia de la factura del eminente español, en la maestría del joven pintor mexicano. El Retrato de mi padre, es prueba de ello, y varios tipos españoles, entre los cuales recordamos una Gitana y una Mujer con Mantilla... que a las claras recuerdan el procedimiento de Zuloaga...

Es posible que Juan Téllez le enseñara lo que había realizado en Europa, ya que mostró un vivo interés por los grabados al aguafuerte que el artista traía como novedad; entre ellos se encontraba uno que le movió a escribir lo siguiente:

Son ejecuciones de primer orden. Entre ellos recordamos... una Bailarina de la India... Aparece en primer término una rara figura 
de mujer bailando una danza curiosa. Con el corselete cubriendo solamente el busto, aparece en una postura altamente sensual, en una expresión del rostro en el cual se nota toda la exhuberancia de la raza. En tanto en el fondo casi oscuro, algunas figuras de musulmanes con lucecillas a sus lados, evocan qúe sé yo cuántas historias dormidas de la Sherezada y de las mil y una noches. ${ }^{9}$

Sobre este tema Téllez pintó también un cuadro que es el que reproduce la figura 19.

Como es la costumbre con todo artista que retorna del extranjero, después de una larga ausencia, a Juan Téllez se le invitó a que expusiera su obra en la academia; la muestra se inauguró a principios de julio, con la asistencia de don Justo Sierra, ministro de Instrucción Pública y Bellas Artes. En la xevista Arte y Letras, apareció un simple comentario, sin firma. ${ }^{10} \mathrm{En}$ él se dio cuenta de algunos cuadros ya conocidos y de otros no mostrados hasta esta fecha; selecciono aquí algunos títulos significativos: El zócalo de Veracruz, Pito Manchego, Un borracho, Anita, Una pesadilla. La exposición incluía también algunas copias de obras famosas, como El bufón don Diego de Acedo, "El Primo", de Diego Velázquez (figura 9) y La mujer del abanico, de Francisco de Goya. Sólo conozco por copia fotográfica el retrato de Una novia, cuadro que llamó bastante la atención de la crítica y asistentes a la muestra; no resisto la tentación de reproducir aquí lo que sobre el mismo se escribiera, pues da idea del gusto y del sentido critico de la época:

... el retrato de novia... es el que mayormente ha llamado la atención de críticos y aficionados, es la obra más reciente del artista y pudiera decirse que es la que caracteriza su estética actual... (La novia) está sentada y vestida con el albeante traje de las desposadas; la belleza del modelo, ha servido sin duda, en mucha parte, para el grande éxito del cuadro; la carne joven, los dulces ojos de virgen y el simbólico todo (sic) ha sido maravillosamente interpretado por ei pintor. ${ }^{11}$

9 Este interesante artículo de autor anónimo fue publicado en El Diario Ilustrado, bajo el siguiente título: "Juan Téllez Toledo. Notables trabajos de un pintor mexicano. Algunos de sus mejores cuadros", el 5 de julio de 1908.

10 "La Exposición de Téllez Toledo", México, julio 12 de 1908, sin número de página.

$11 I d$. 
Después del éxito que Téllez obtuvo con la muestra de su obra en la academia, se apagaron hasta donde estoy informado los comentarios siempre favorables que le dedicara la crítica de arte, con José Juan Tablada a la cabeza. Por Abelardo Carrillo y Gariel nos informamos que antes de que finalizara 1908, se "... marchó a New York, E.U.A., y allí dio muestras de padecer el trastorno mental que obligó a su familia a traerlo a México en 1910 e internarlo en el manicomio de La Castañeda el 26 de agosto de 1916". ${ }^{12}$ Algo semejante había anotado ya Justino Fernández, sin ofrecer mayor comentario sobre la causa o razón de tal fatalidad, "... en 1910 perdió la razón en New York y se le trajo en ese estado al lado de su familia".13

¿Qué fue lo que pintó Juan Téllez entre 1908 año de su retorno a México y el de 1910 en que enloqueció? ¿Qué le llevó a la Babel de Hierro? ¿En Europa había presentado ya algún síntoma de trastorno mental? Es posible, si nos atenemos al contenido de una carta que le escribió Rubén Darío desde Madrid el 17 de julio de 1908. "En esa carta Rubén consuela a Téllez por la desgracia que ha sufiido y le insta para que se refugie en el trabajo." 14 Las otras preguntas quedan por hoy sin contestación.

Vista a la distancia del tiempo la pintura del infortunado artista, se nos presenta, de acuerdo con José Juan Tablada, como una proposición aceptable para liquidar los gastados hábitos de un gusto anticuado, que existía en la academia entre los seguidores de la llamada "Escuela de Clavé". La vieja institución en cuanto tal, no podia dar más, a pesar de la presencia del pintor catalán Antonio Fabrés. ${ }^{15} \mathrm{La}$ renovación que se esperaba sólo podía venir de parte de los pensionados en Europa, no obstante que éstos se mostraron refractarios a los grandes cambios que las vanguardias realizaban; meditemos en lo que ya habían hecho a principios de siglo, figuras tales como Gauguin, Cézanne, Matisse, los expresionistas alemanes y desde luego Picasso, quien en 1907 habia pintado ya, nada menos que esa obra que es capi- . tal en la historia del arte de este siglo, Las señoritas de Aviñón. No, ninguno de los pensionados pudo vislumbrar el quiebre fundamental

12. Op. cit.

13 El arte moderno en México, p. 189.

14 Cita de Antonio Oliver, "Presencia de México en el Archivo de Rubén Dario de Madrid", Universidad de México, México, marzo de 1958, vol, xir, núm. 7.

15 Sobre este tema consúltese el estudio de Salvador Moreno El pintor Antonio Fabrés, México, UNAM, Instituto de Investigaciones Estéticas, 1981. 
DOI: http://dx.doi.org/10.22201/iie.18703062e.1983.52.1190

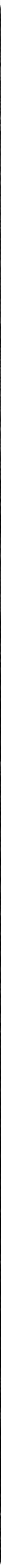

Figura 1. Juan Téllez. Autorretrato con calavera. 1907. Óleo Tela. 0.95 x $0.80 \mathrm{mts}$. 
DOI: http://dx.doi.org/10.22201/iie.18703062e.1983.52.1190

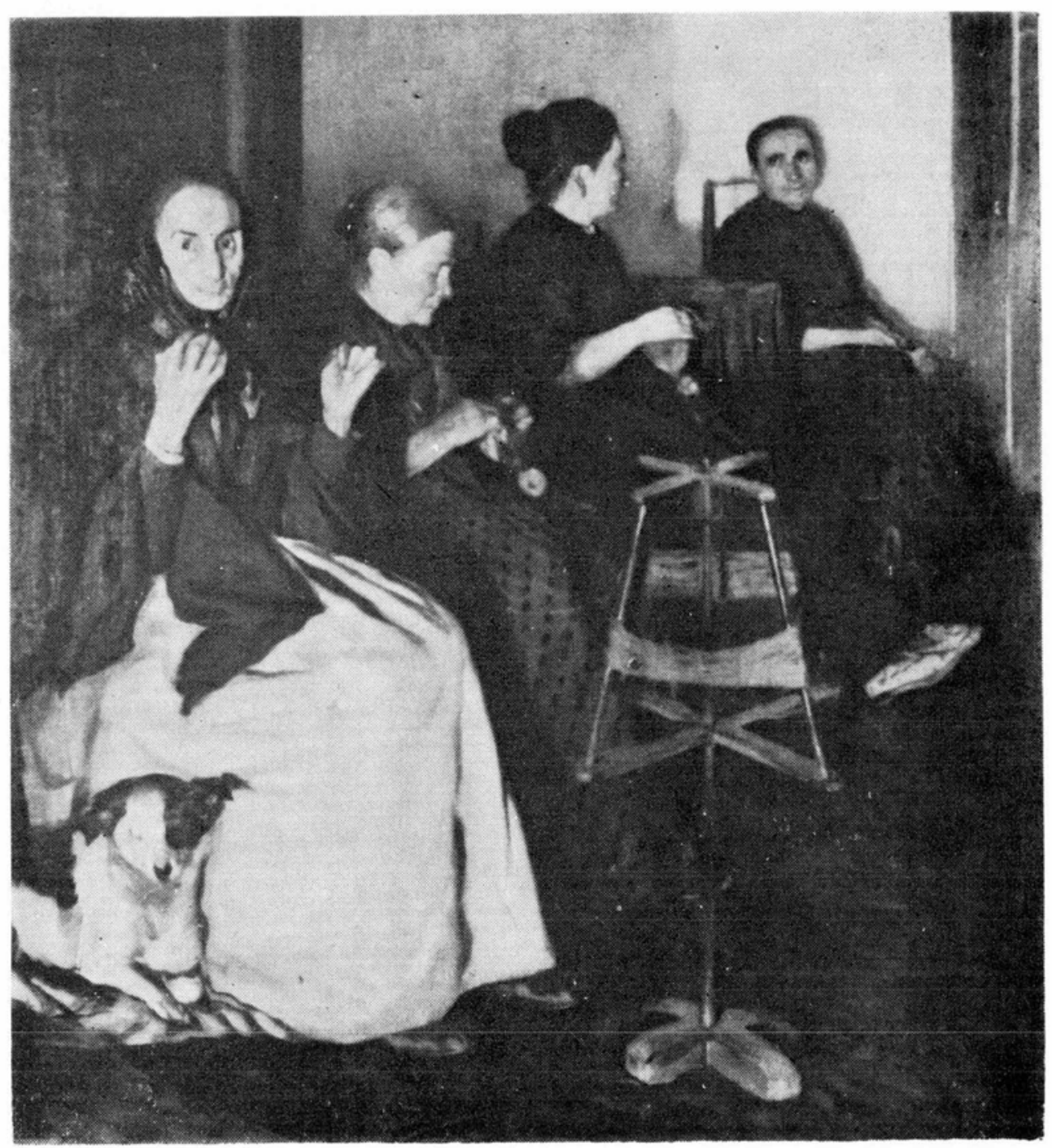

Figura 2. Juan Téllez. La labor. Óleo Tela. 


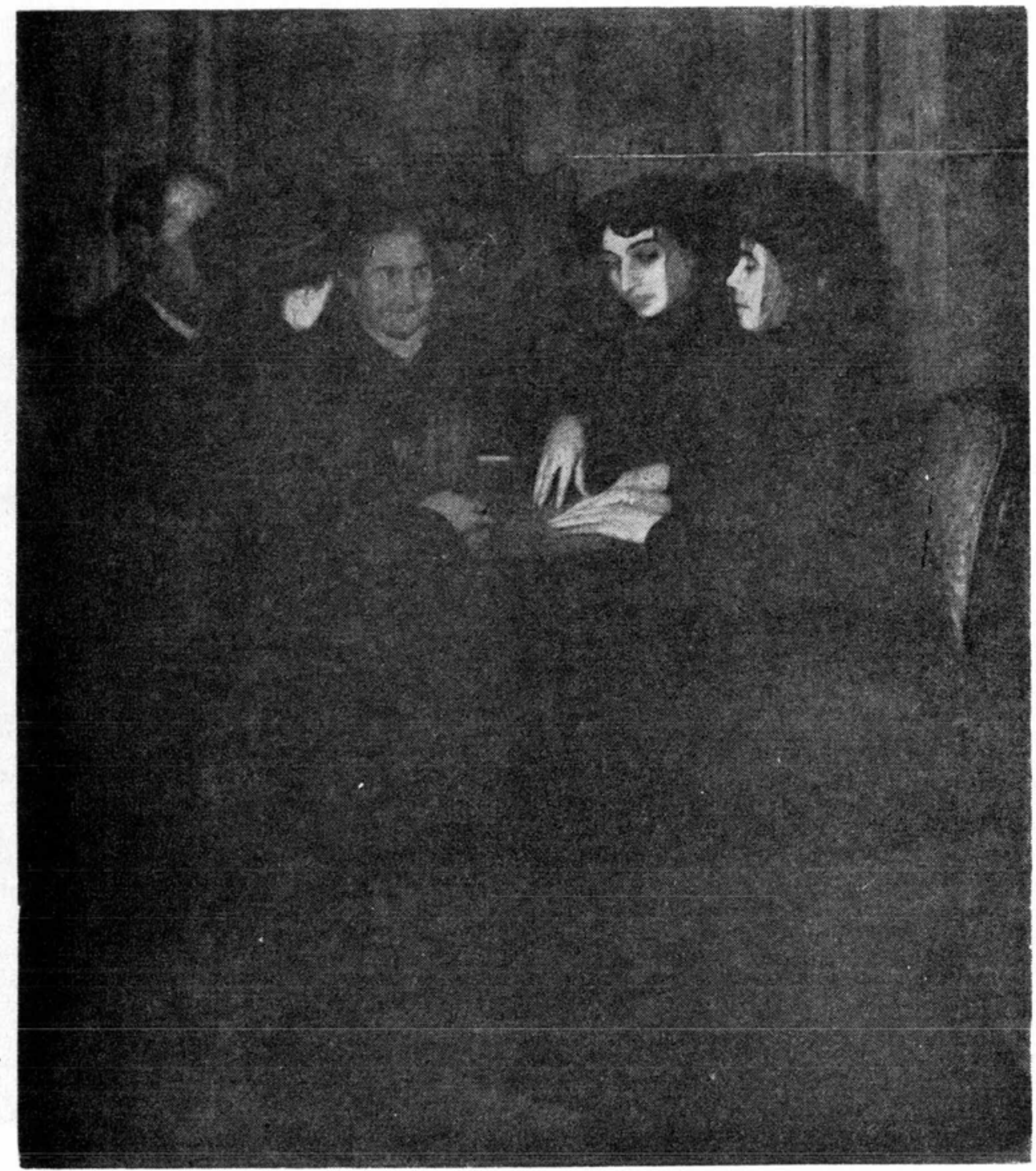

Figura 3. Juan Téllez. Las espiristas, 1904? Óleo Tela. 
DOI: http://dx.doi.org/10.22201/iie.18703062e.1983.52.1190

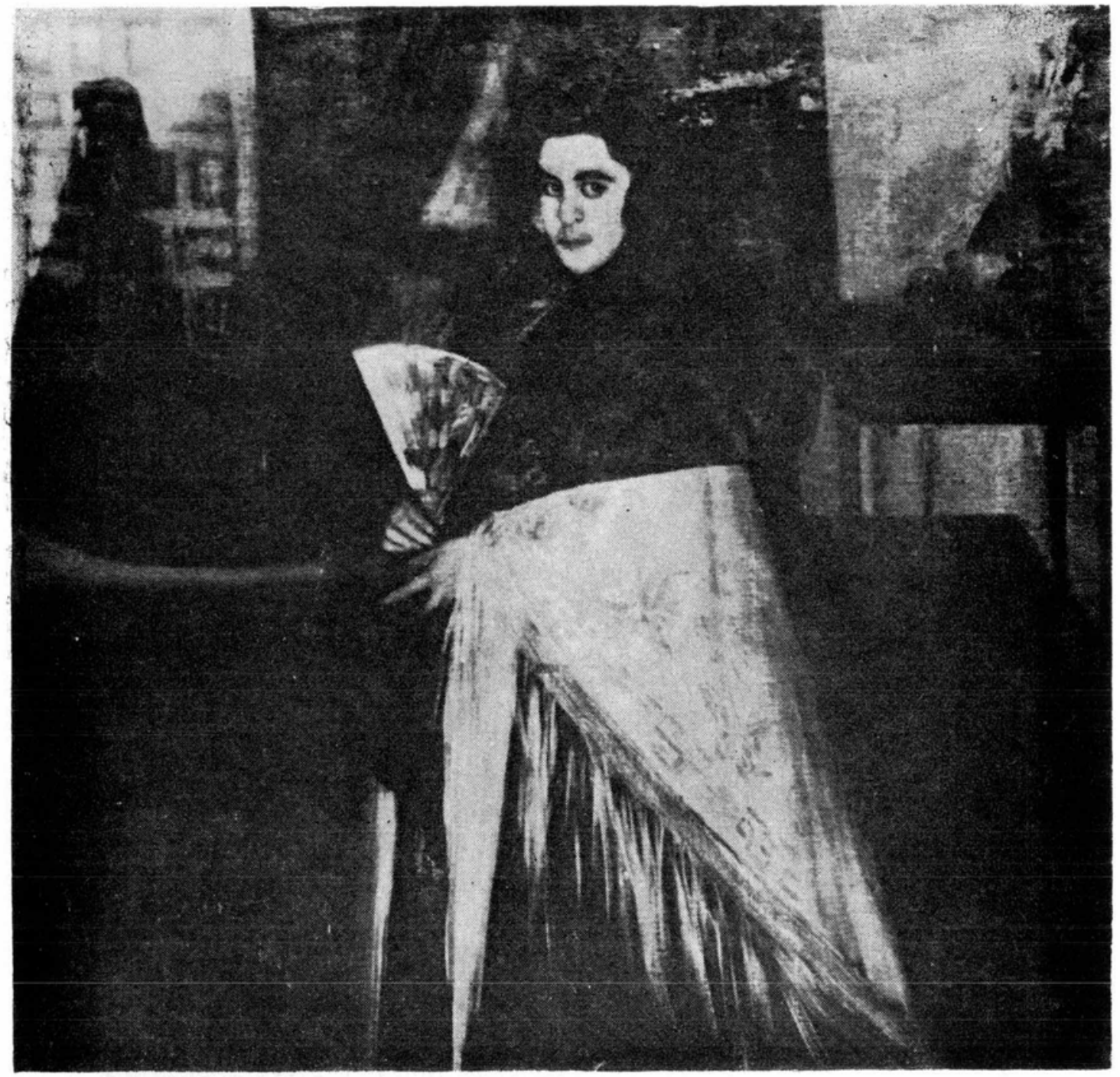

Figura 4. Juan Téllez. Mujer española. 1904. Óleo Tela. 
DOI: http://dx.doi.org/10.22201/iie.18703062e.1983.52.1190

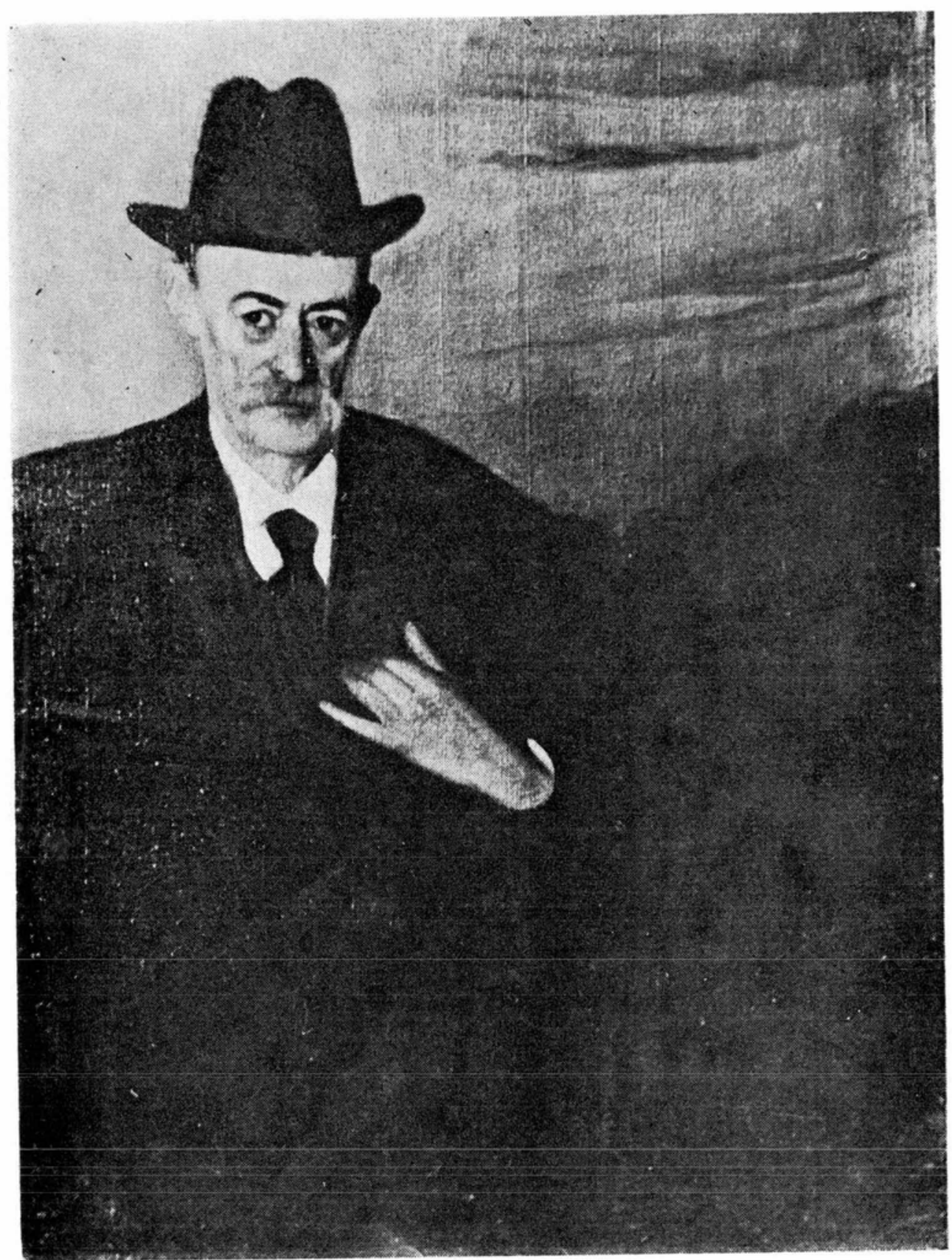

Figura 5. Juan Téllez. El Padre del pintor óleo Tela. 


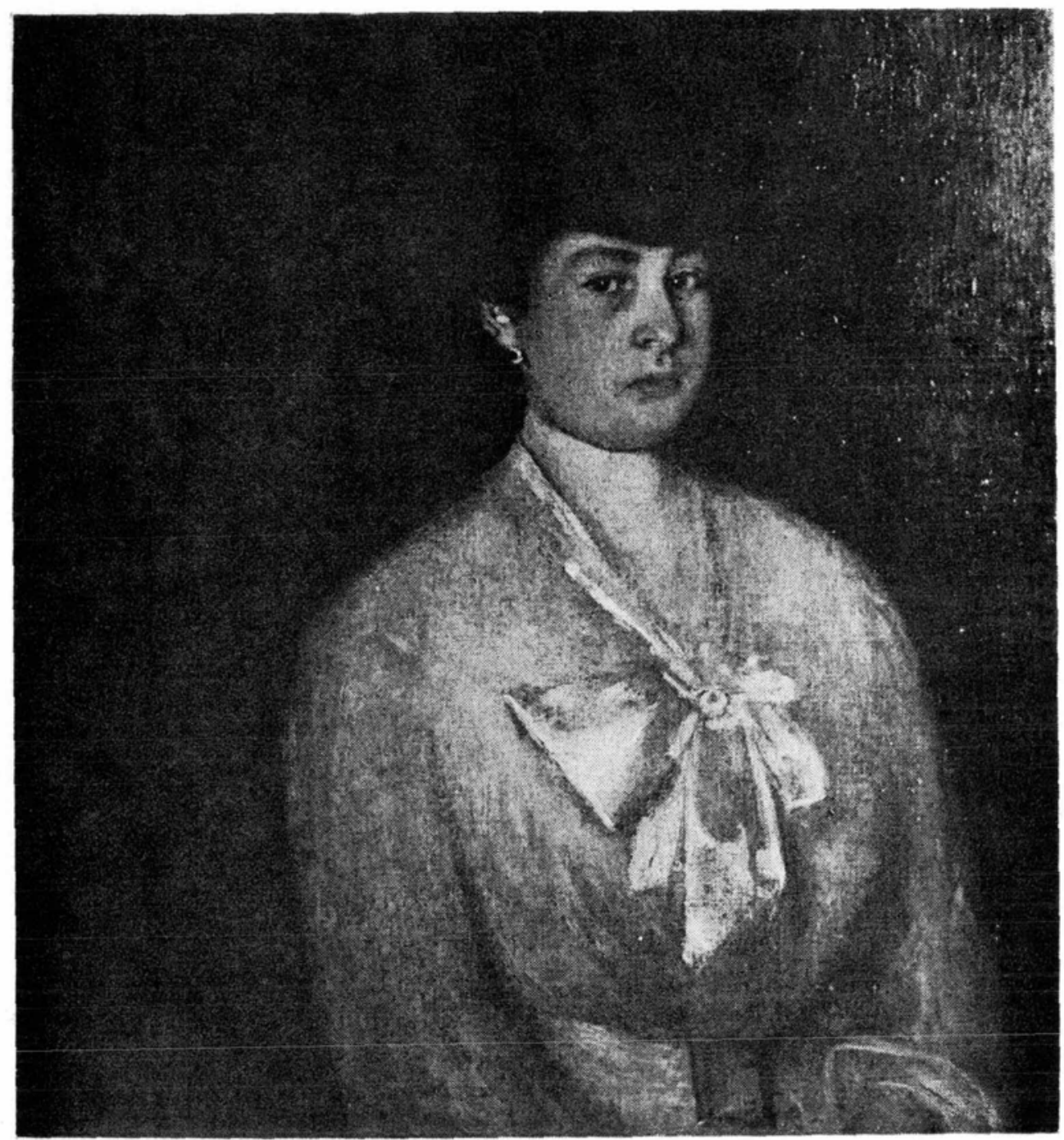

Figura 6. Juan Téllez. La Hermana del pintor. 1906. Óleo Tela, 0.80 x 0.80 mts. 


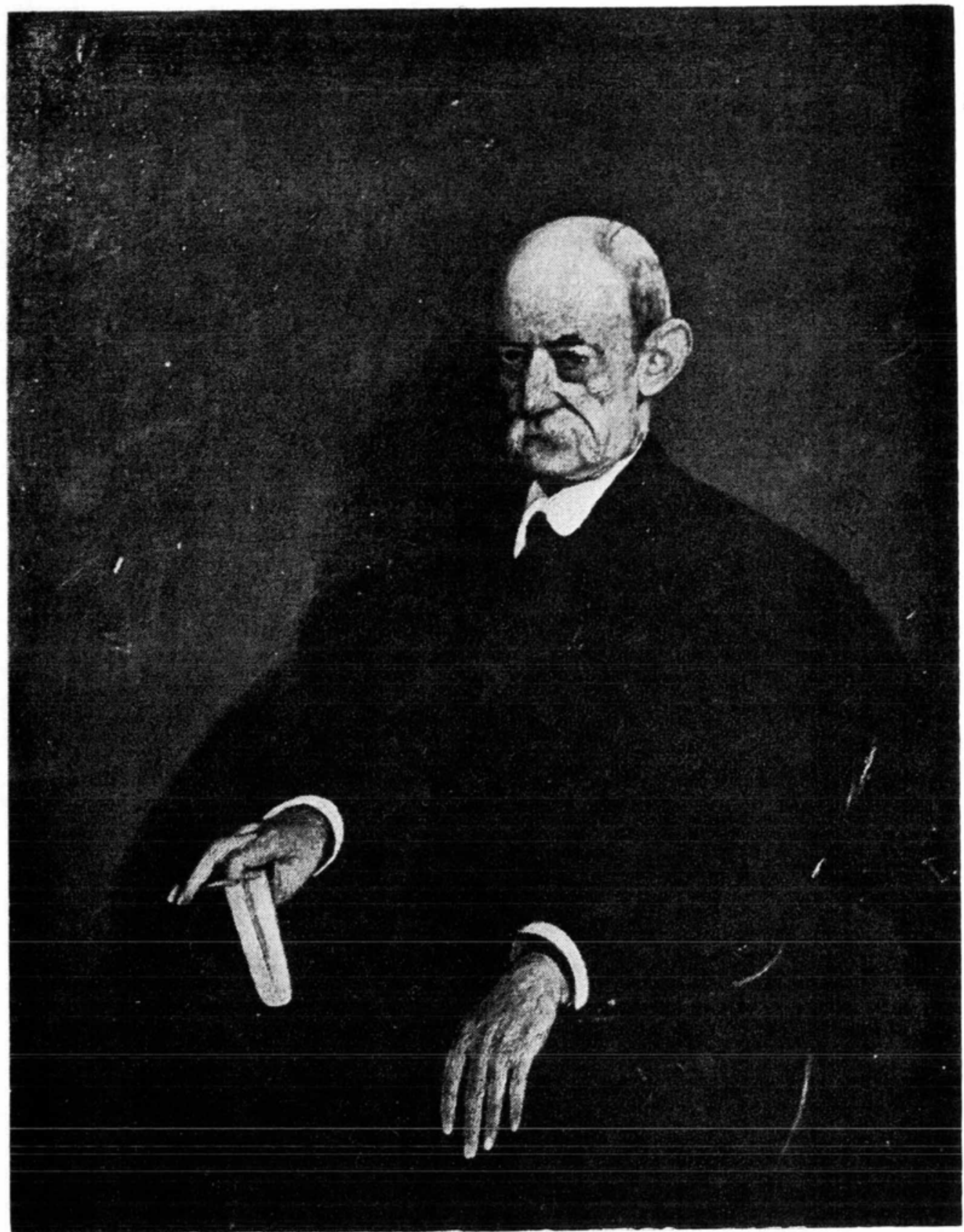

Figura 7. Juan Téllez. El padre del pintor. 1906. Óleo Tela. 0.96 x 0.81 mts. 


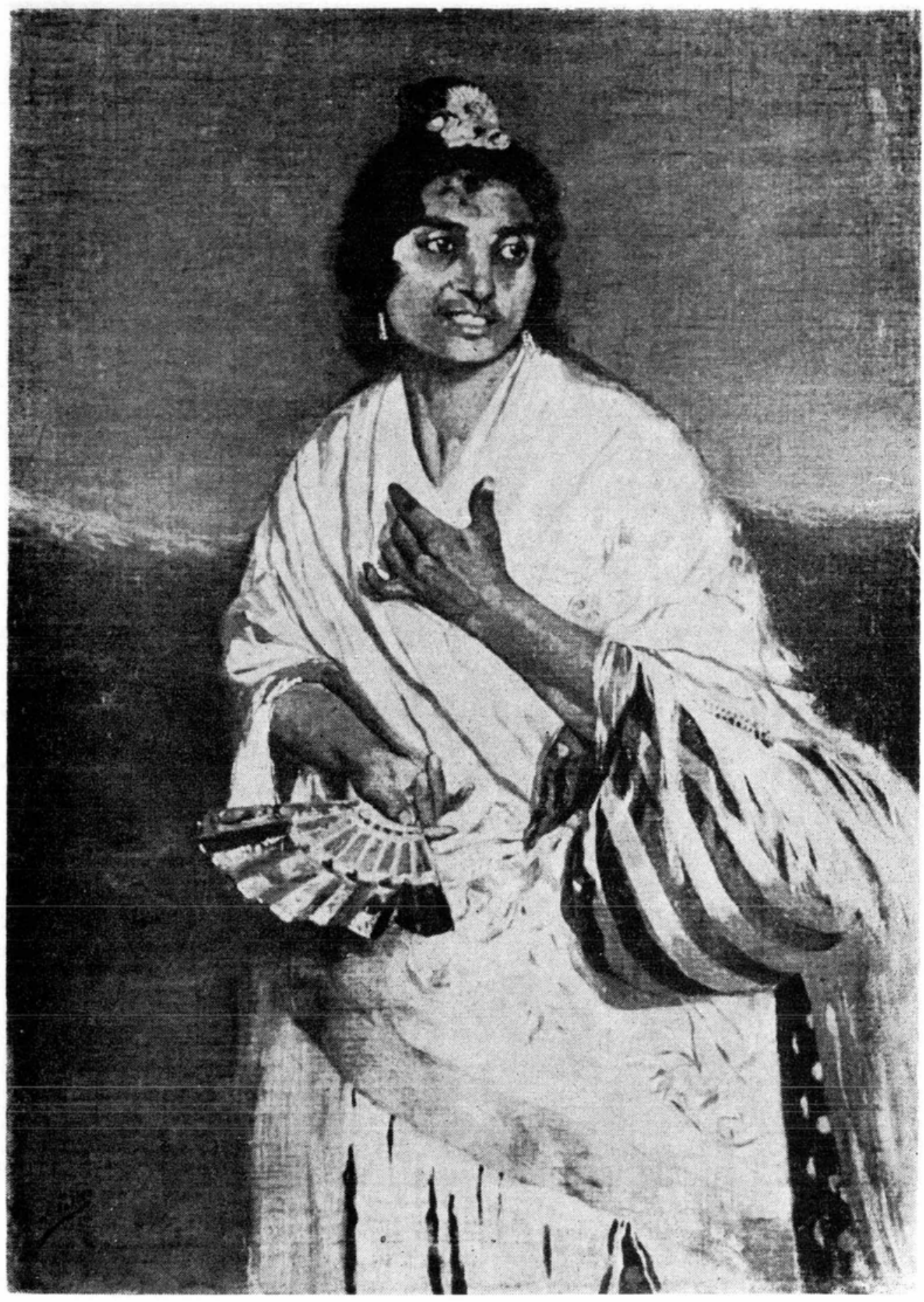

Figura 8. Juan Téllez. La gitana. 1907. Óleo Tela. $1.02 \times 0.71 \mathrm{mts}$. 
DOI: http://dx.doi.org/10.22201/iie.18703062e.1983.52.1190

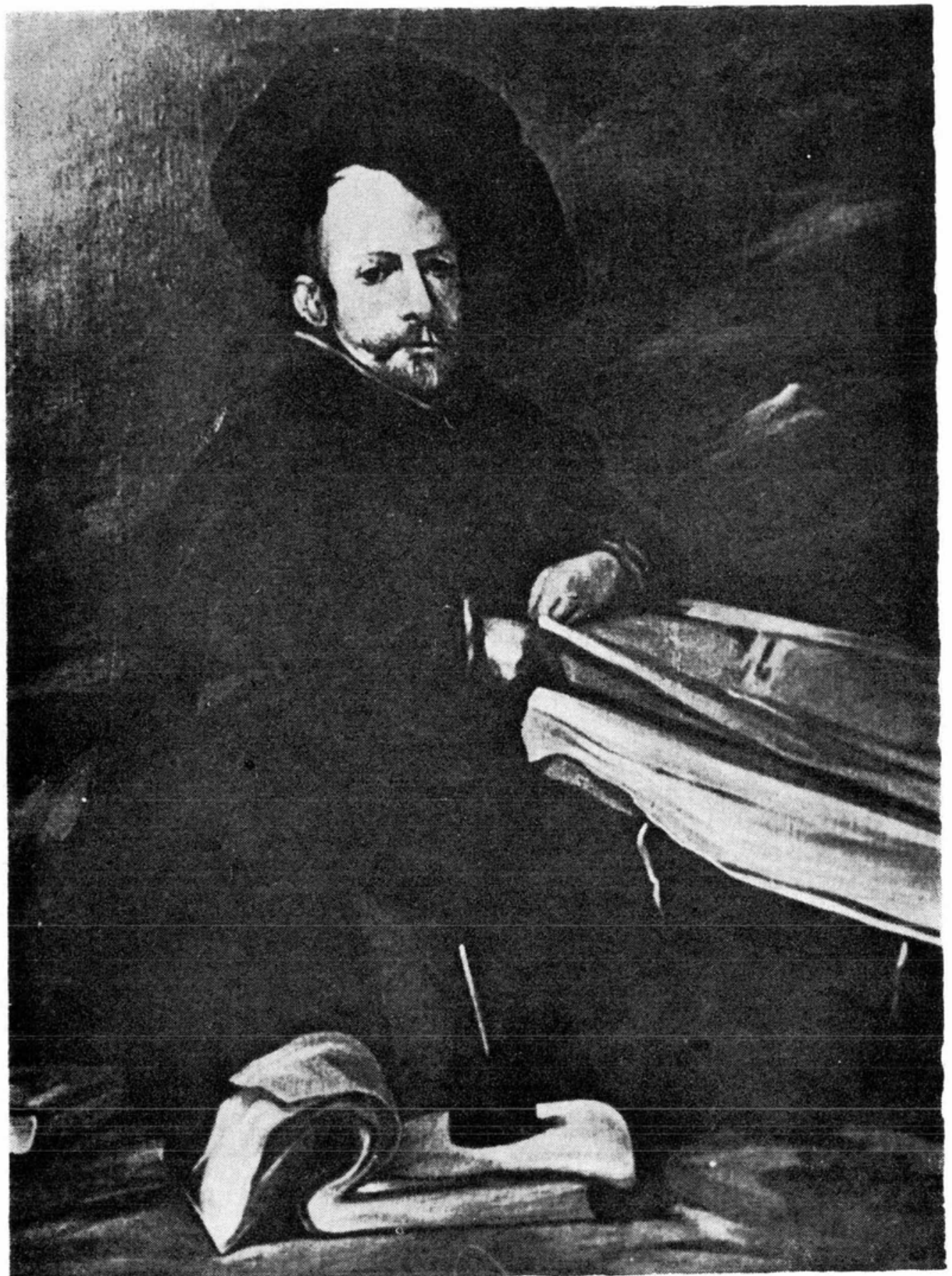

Figura 9. Juan Téllez. Copia de Velázquez. El Bufón Don Diego de Acedo, "El Primo". 1907? Óleo Tela, 
DOI: http://dx.doi.org/10.22201/iie.18703062e.1983.52.1190

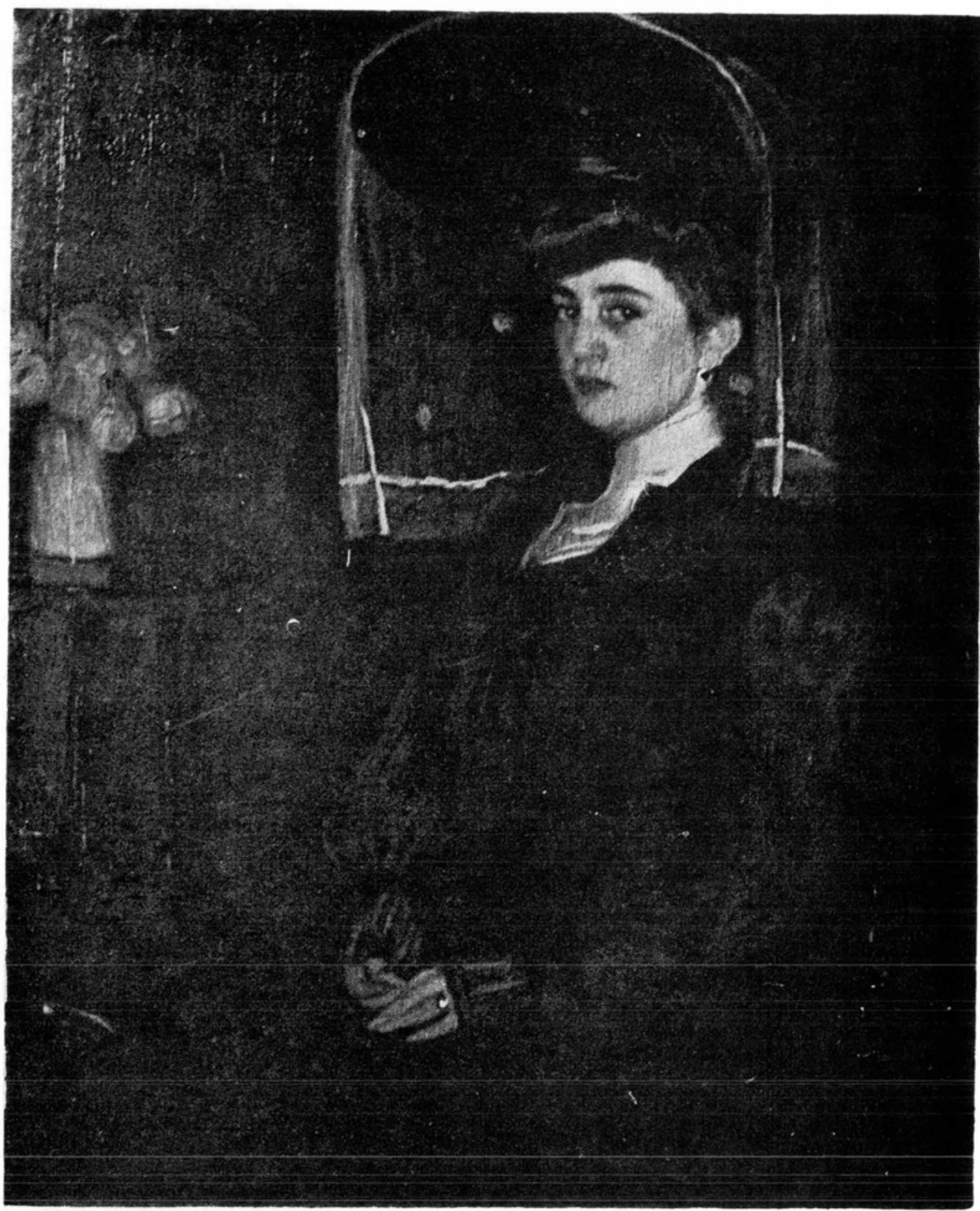

Figura 10. Juan Téllez. Retrato de Matilde. 1908, Óleo Tela 1.10 x 0.87 mts. 
DOI: http://dx.doi.org/10.22201/iie.18703062e.1983.52.1190

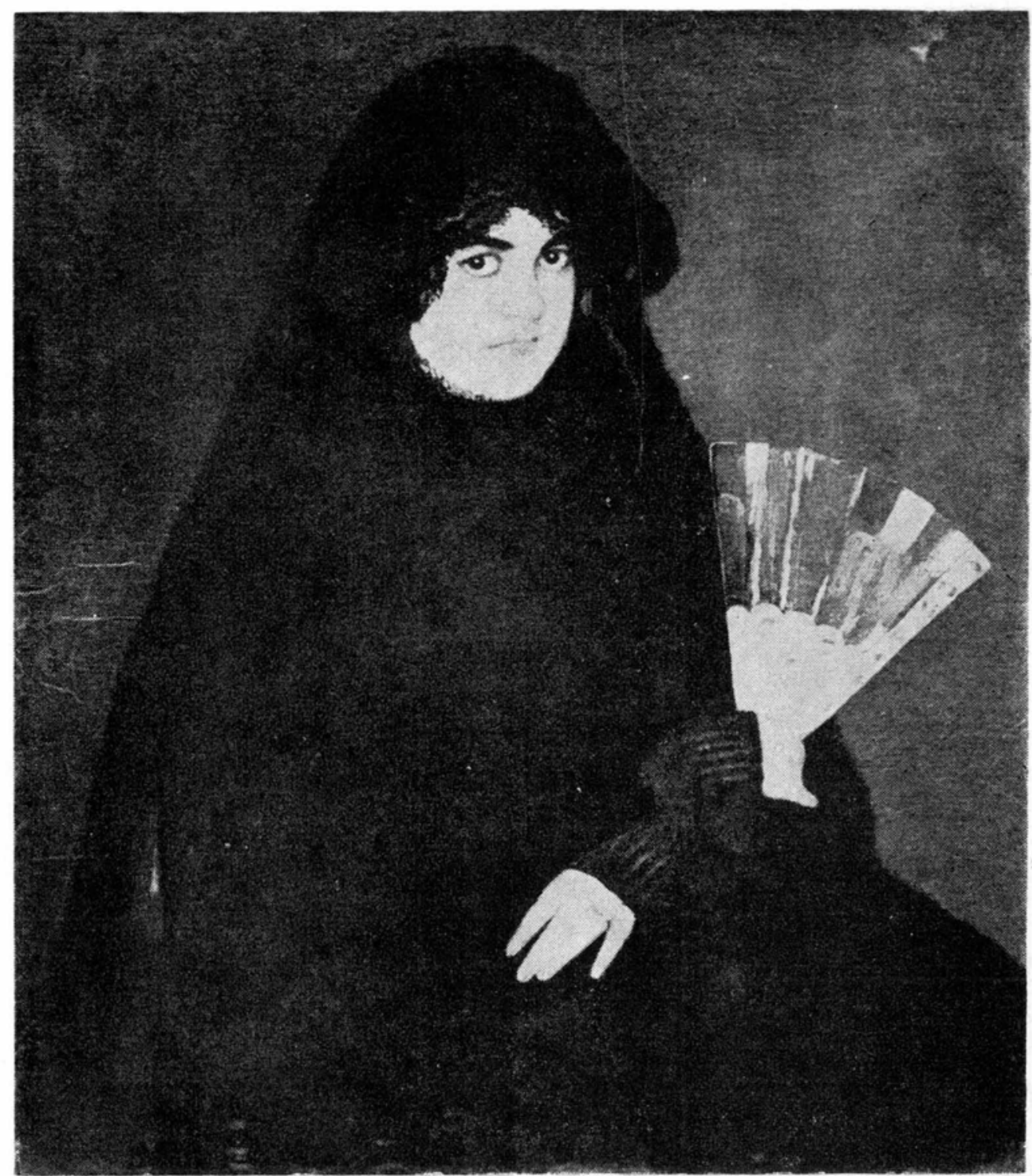

Figura 11. Juan Téllez. Mujer del abanico. Óleo Tela. 1.16 x 0.89 mts. 


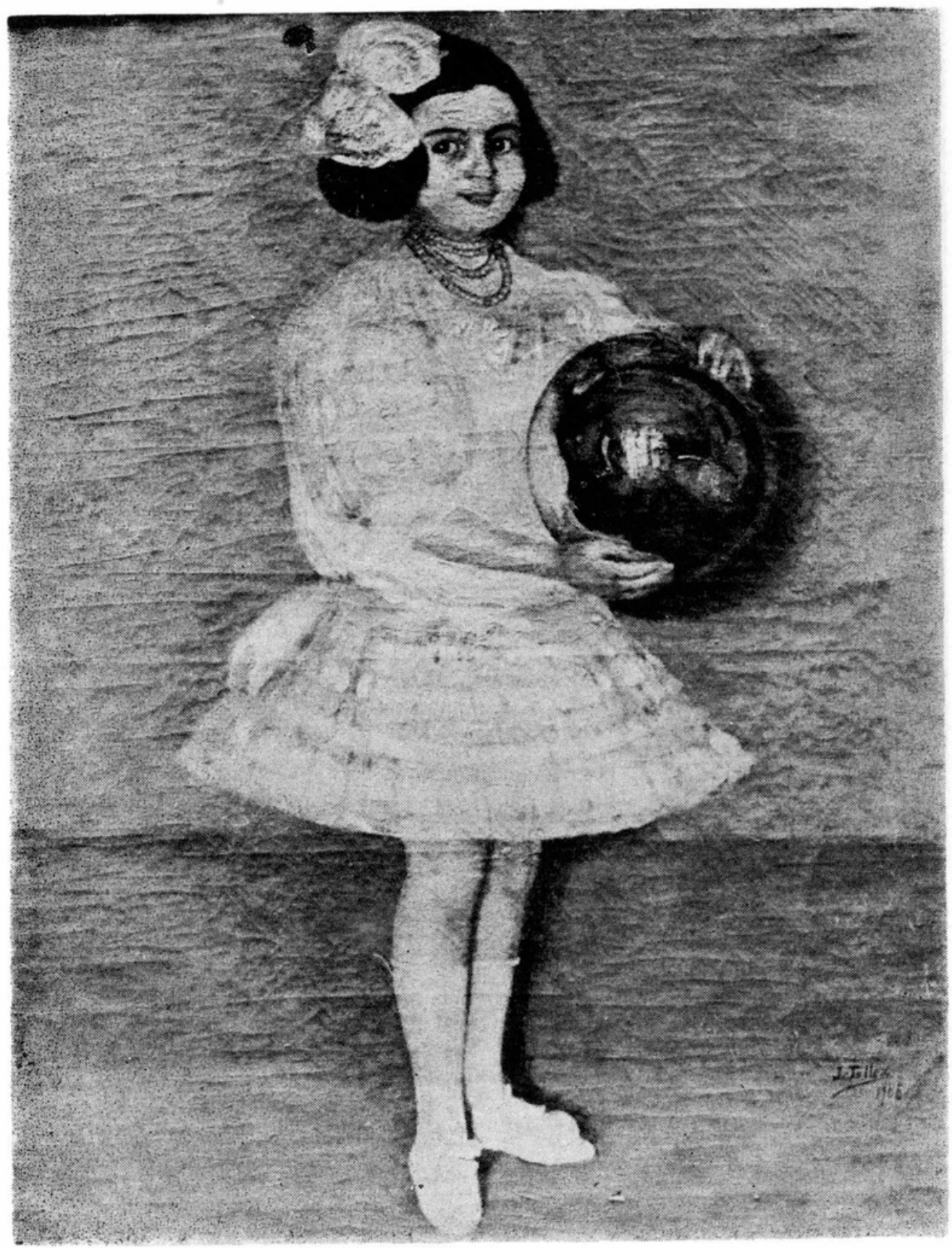

Figura 12. Juan Téllez. Evita. 1908. Óleo Tela. 1.16 x 0.89 mts. 
DOI: http://dx.doi.org/10.22201/iie.18703062e.1983.52.1190

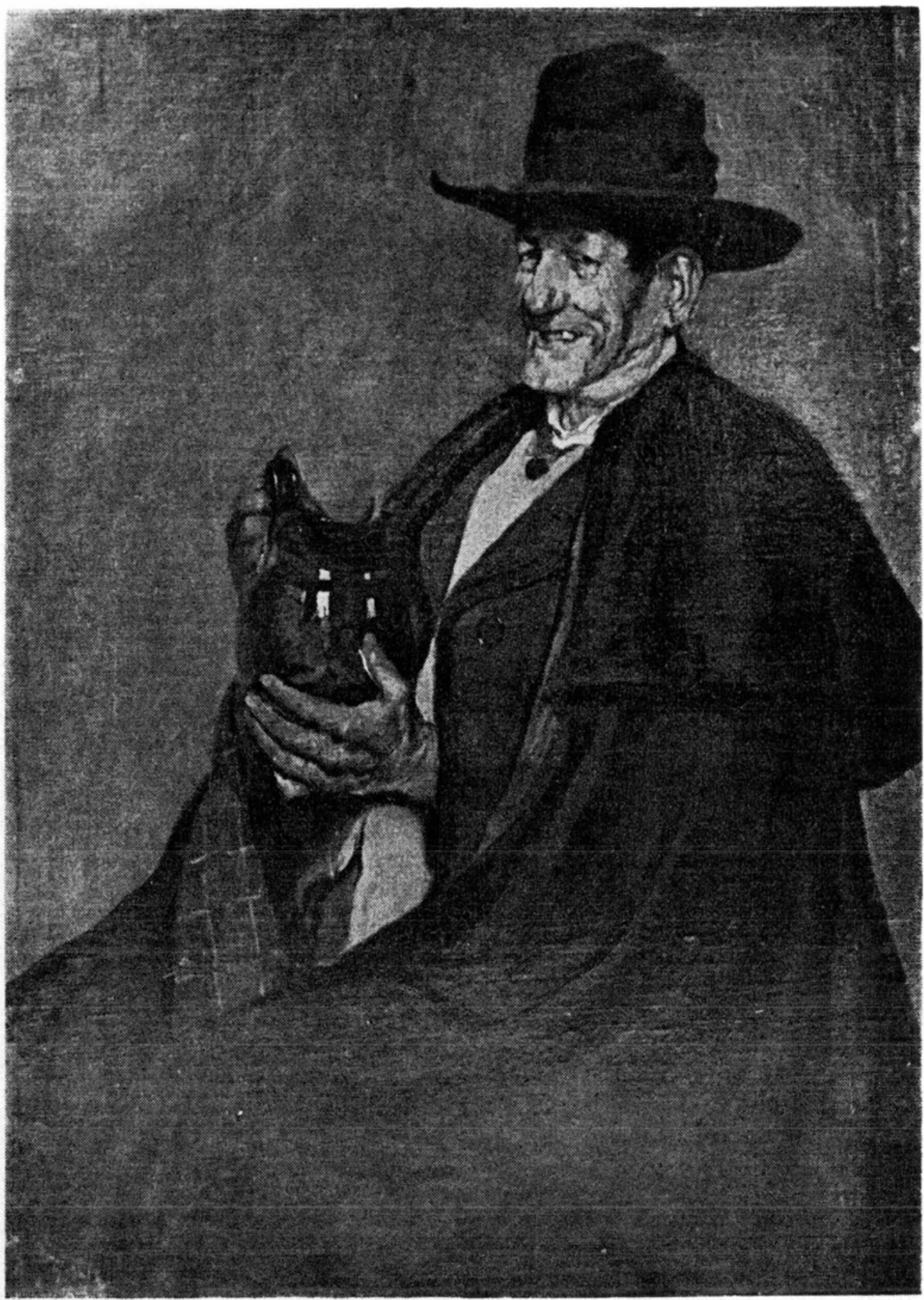

Figura 13. Juan Téllez. El viejo de la jarra. Óleo Tela. 1.10 x 0.87 mts. 
DOI: http://dx.doi.org/10.22201/iie.18703062e.1983.52.1190

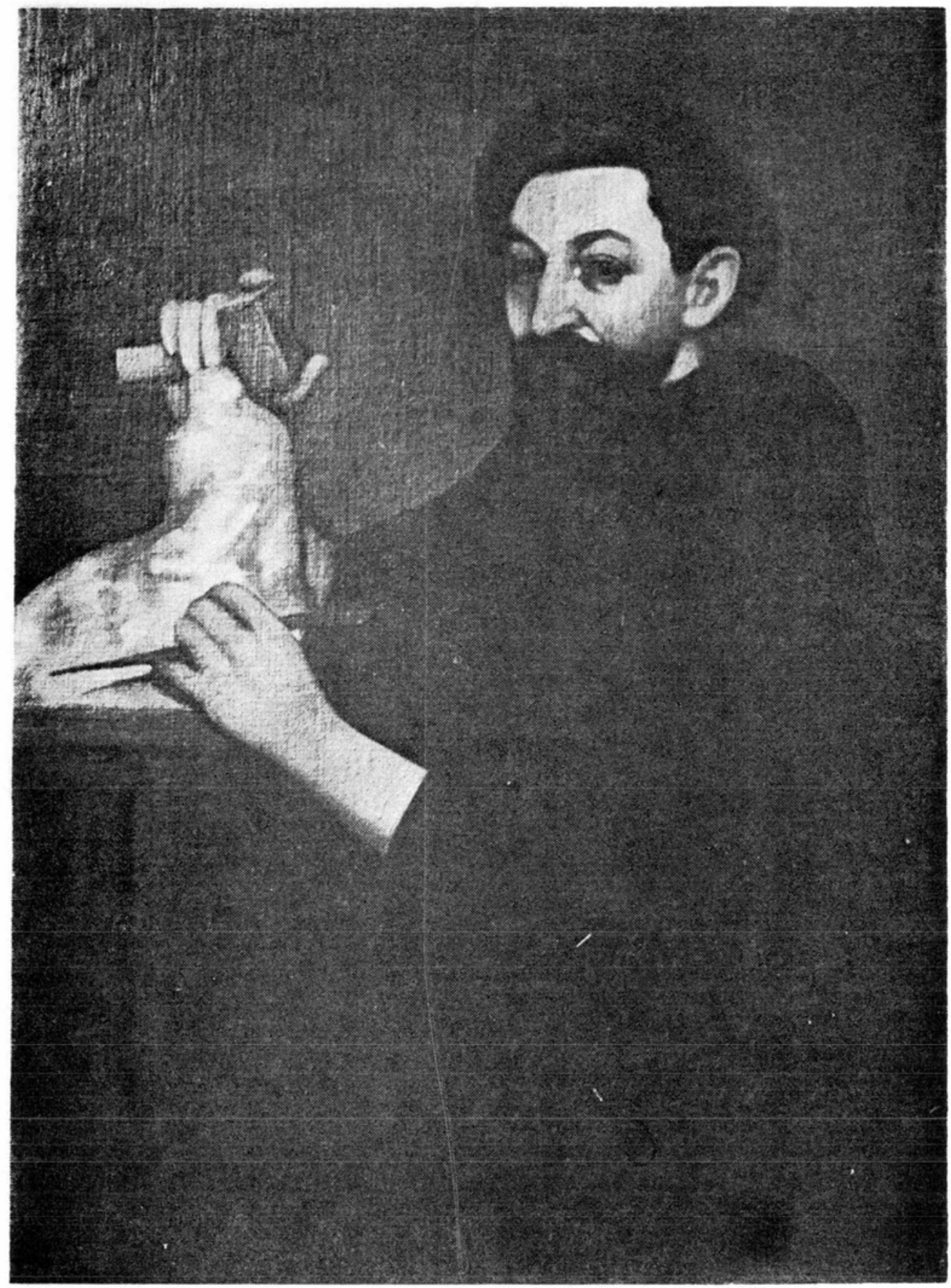

Figura 14. Juan Téllez. Retrato de un escultor. Óleo Tela. 0.96 x 0.81 mts. 
DOI: http://dx.doi.org/10.22201/iie.18703062e.1983.52.1190

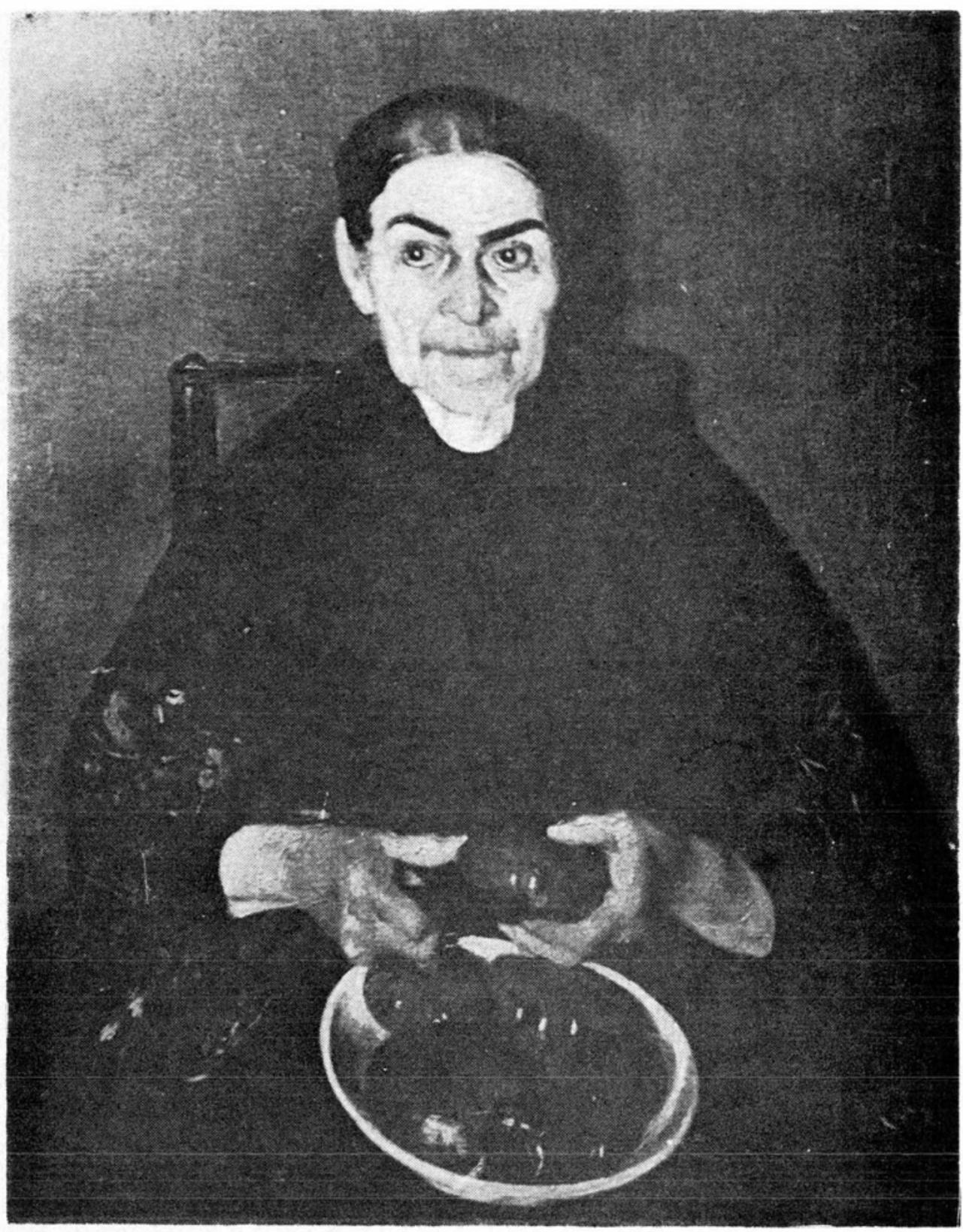

Figura 15. Juan Téllez. Mujer mondando verdura. Óleo Tela. 1.05 x 0.82 mts. 


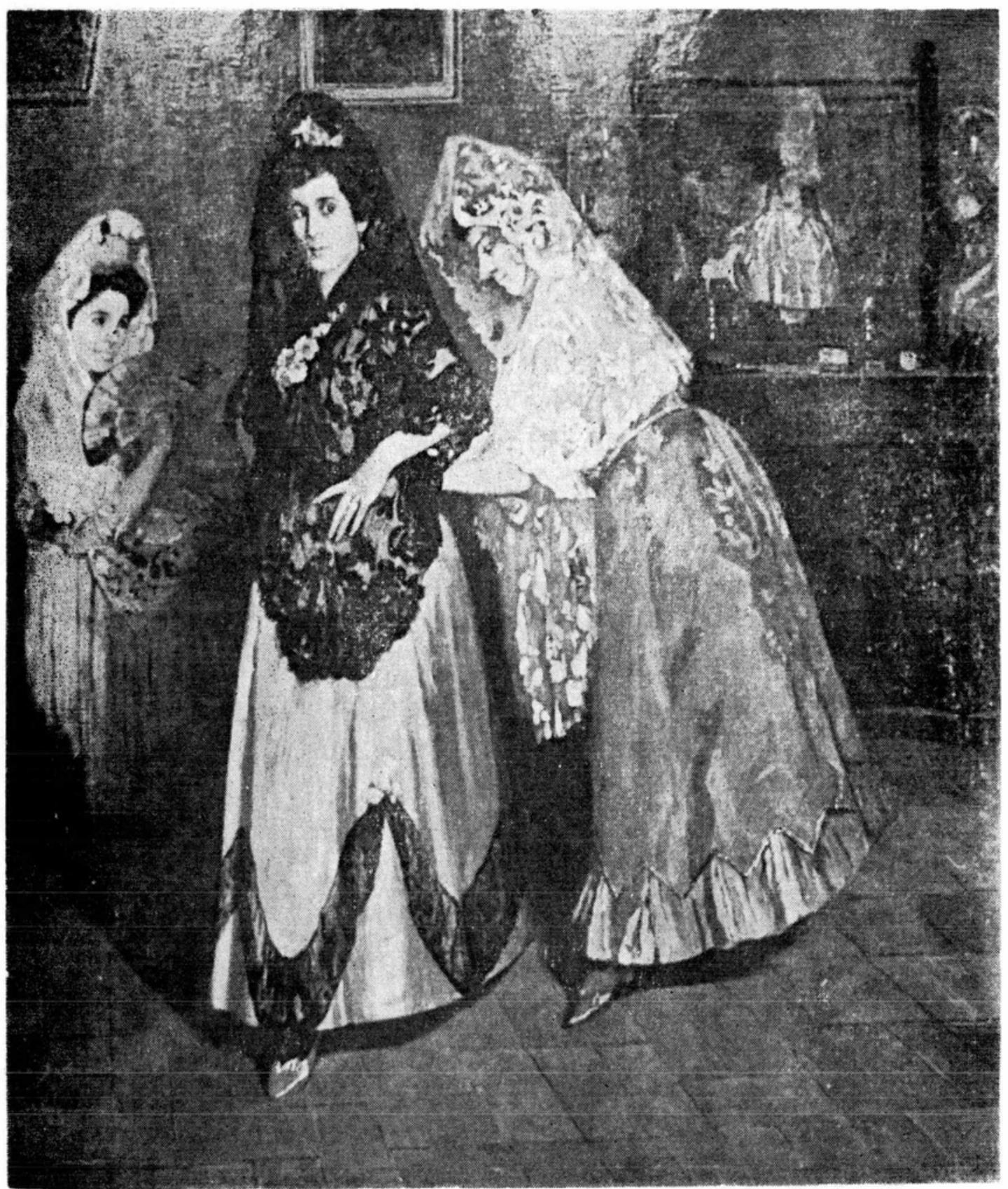

Figura 16. Juan Téllez. Mujeres de España. 1907. Óleo Tela. 2.10 x 1.90 mts. 
DOI: http://dx.doi.org/10.22201/iie.18703062e.1983.52.1190

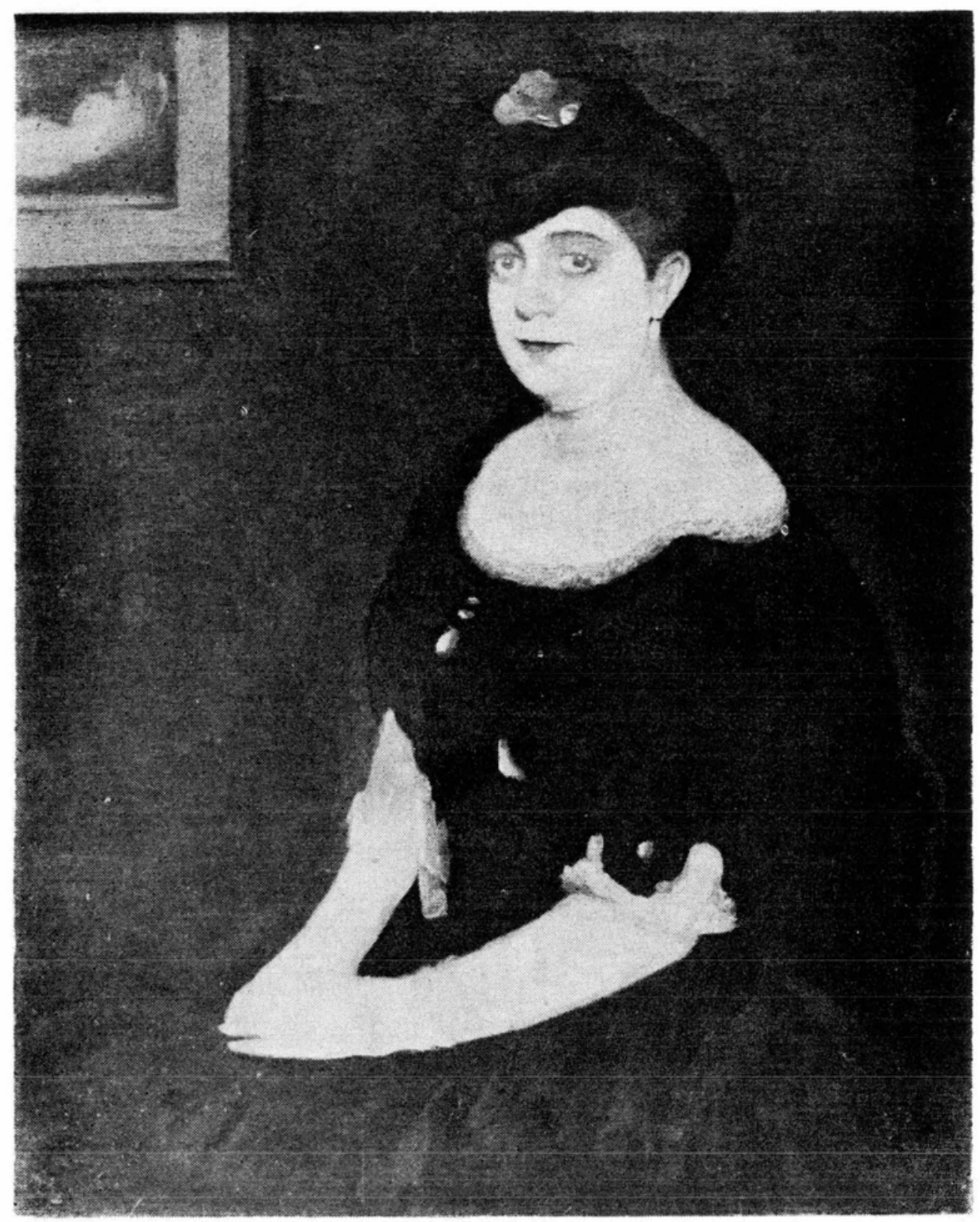

Figura 17. Juan Téllez, La hermana del pintor. 1908. Óleo Tela. 1.16 x $0.82 \mathrm{mts}$. 
DOI: http://dx.doi.org/10.22201/iie.18703062e.1983.52.1190

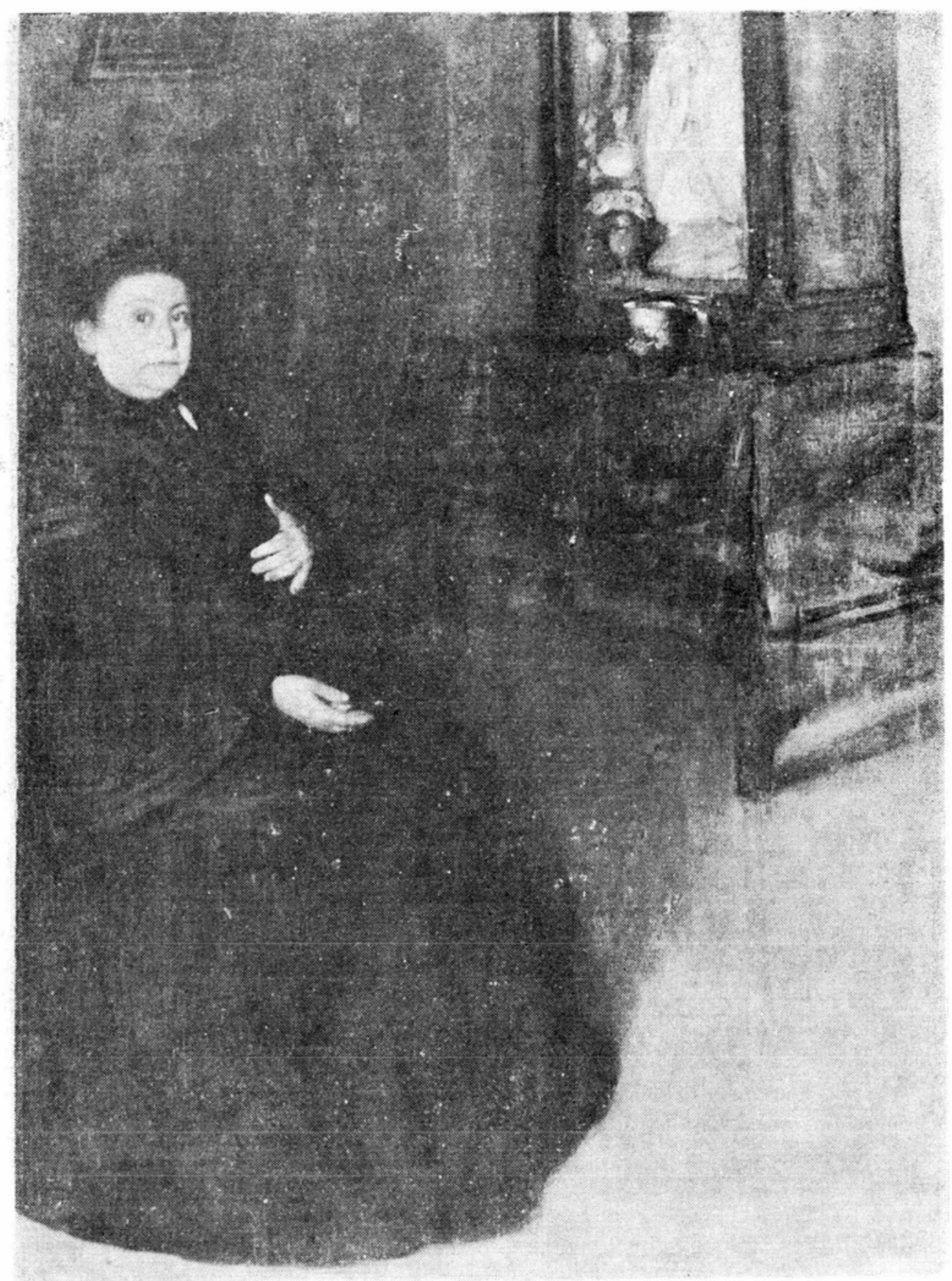

Figura 18. Juan Téllez. La madre del pintor. Óleo Tela. 1.80 x $1.28 \mathrm{mts}$. 


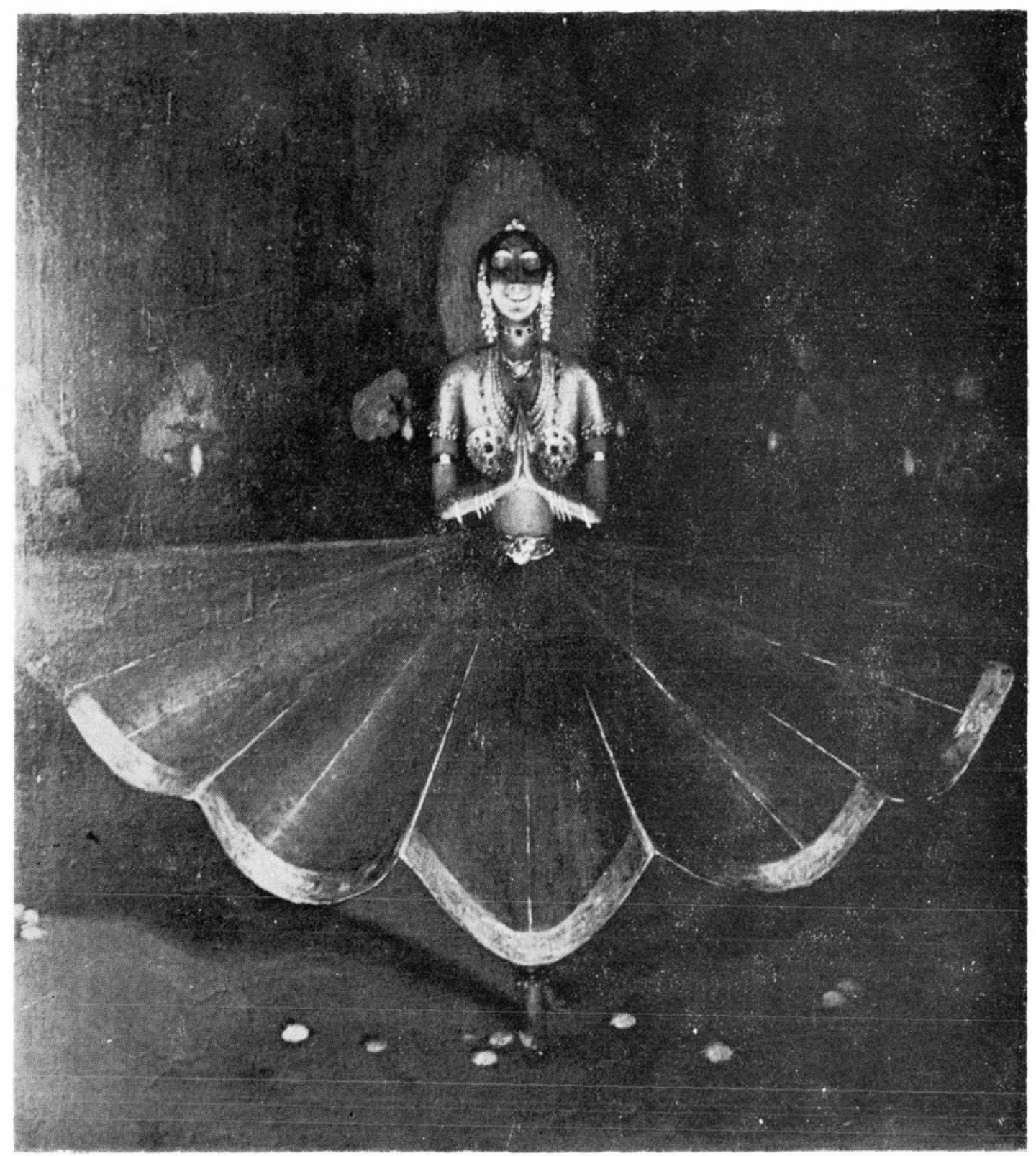

Figura 19. Juan Téllez. Bailarina de la India. 1907. Óleo Tela. 1.38 x 1.31 mts. 
DOI: http://dx.doi.org/10.22201/iie.18703062e.1983.52.1190

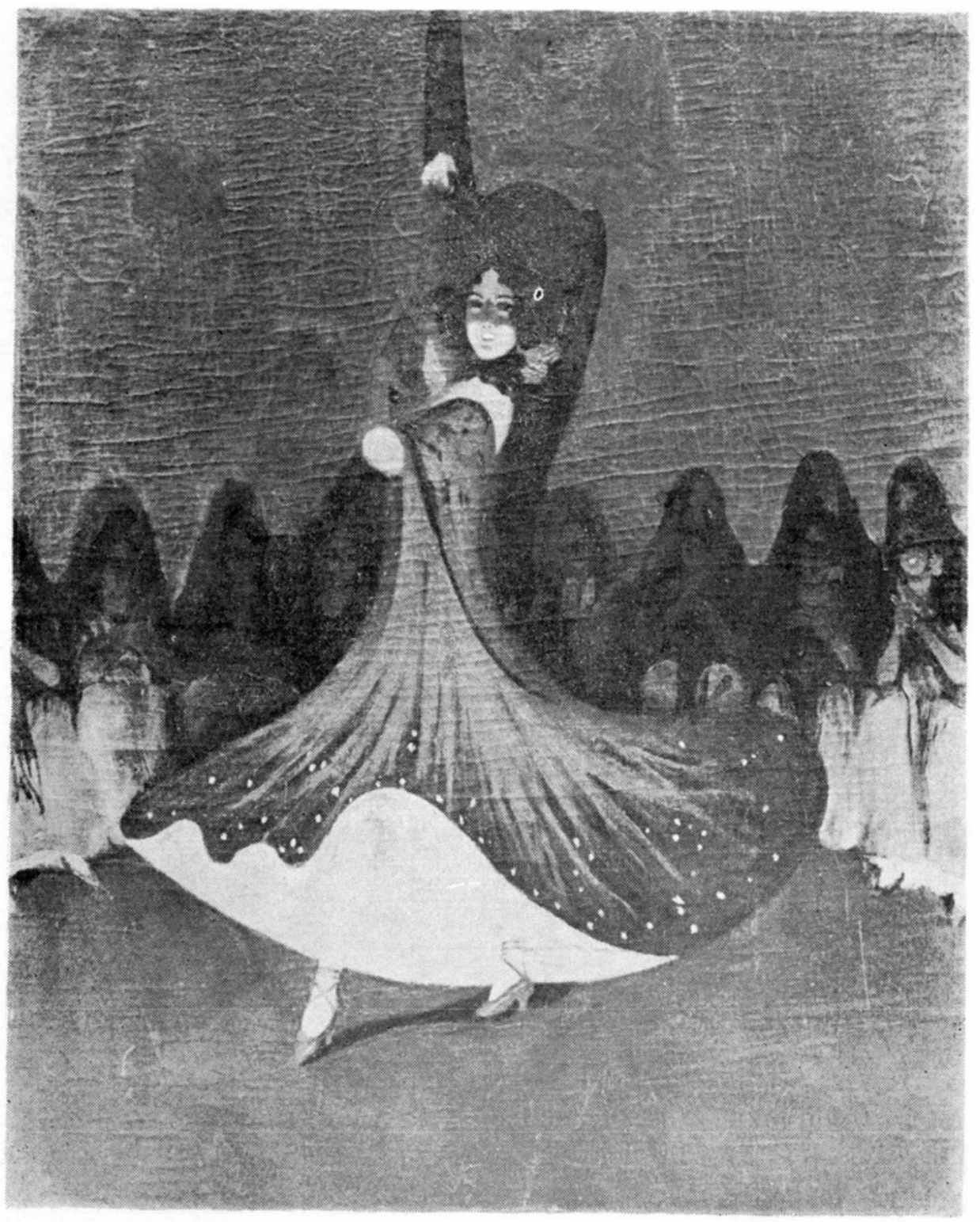

Figura 20. Juan Téllez. Danza española. Óleo Tela. 0.96 x $0.82 \mathrm{mts}$. 
que aquéllos dieron; por esa razón he anotado, líneas atrás, que lo que proponía Téllez era aceptable para el medio provinciano del momento, puesto que la autoridad institucional de la Academia de Arte se mostraba cerrada para aceptar cualquier cambio que atentara contra los principios largamente establecidos; el caso mexicano no era único; basta con recordar que una postura semejante guardaban las corporaciones académicas de Alemania, Inglaterra, España y, por supuesto, Francia, a pesar de que los artistas de vanguardia habian principiado la lucha contra la tradición desde mediados del siglo xIx.

Por otra parte, en el año en que el pintor perdió la razón, se inició en México un cambio trascendental de consecuencias no previstas en ese momento, con el estallido de la Revolución Maderista. Este movimiento político de carácter popular, despertó en el país una conciencia de tipo nacionalista, que en el terreno de las artes propició, años adelante, la aparición de la pintura mural. ¿Téllez se habría adaptado a la nueva situación? Recuérdese que se veía en él a un posible candidato para las obras decorativas del Teatro Nacional, hoy Palacio de Bellas Artes. ¿Se le habría dado la oportunidad como sucedió en 1916 con Saturnino Herrán? Estas preguntas suenan a necedad, no obstante, me aventuro a afirmar que él no habría encontrado el ambiente propicio para realizar una obra que le identificara con una nación a la cual, en verdad, no conocía; él tenía las raíces echadas en España, su espíritu y su estética estaban allá; así lo muestran, al menos, las pinturas que aquí se reproducen.

En efecto, todas muestran un acentuado españolismo en el gusto de Juan Téllez, ya sea en su carácter pictórico como asimismo en los temas desarrollados. Lo primero que llama la atención en sus telas es el predominio de los negros, el betún que empleó pródigamente y que, por cierto, le mereció una censura de Pedro Henríquez Ureña ${ }^{10}$ Una España sombría, densa a la vez que profundamente realista en sus tipos y costumbres, es la que entrega en esos cuadros. Suele ligarse a Téllez, no sin cierta xazón, con Ignacio Zuloaga, el célebre maestro de la pintura española de principios de siglo; mas éste no fue capaz de sumir lo español entre las profundidades del betún. éDe dónde procede la tendencia? Desde luego no de los maestros contemporáneos de Téllez, sino del Prado y los museos de provincia que visitó, de las iglesias y

10 La referencia se encuentra en su ensayo "Don Juan Ruiz de Alarcón". Véase Obrá Critica, México, 1960, p. 273. 
conventos donde se guarda la pintura tenebrista de Zurbarán, del Españoleto y de Francisco Ribalta; de la pintura del Siglo de Oro Espa. ñol proviene el tenebrismo que aceptó porque no fue capaz de ver otra cosa este artista de temperamento saturniano. El realismo de los maestros citados le impactó profundamente; tal hecho salta a la vista en cuadros como La labor, Mujer española, El viejo de la jarra y Mujer mondando venduras. Dada la identificación de Téllez con la pintura española, no deja de sorprender la ausencia del tema religioso en su obra conocida; nada habría sido tan apropiado para él, que una escena de la Pasión de Jesús; sin embargo, parece ser que estuvo lejos de la pintura religiosa.

Una preferencia por las composiciones en espacios interiores se advierte en las telas de Juan Téllez; se trata de estancias en las cuales las penumbras están por dominarlo todo, cuando no se encuentran invadidas ya por la negrura de las sombras mismas que sirven, por otra parte, de fondo para la vibración de los colores vivos, colores que imponen asi su propia autonomía. En la disposición de esos interiores, por regla general, solamente se encuentra una figura; los elementos complementarios de las composiciones son escasos y no llegan a repetirse: un búcaro de rosas, una imagen religiosa, y en dos retratos femeninos aparecen, en uno, un cisne de largo cuello, en tanto que en el otro hay un cuadro que contiene un desnudo tirado de espaldas al espectador (ver figuras 6 y 17 ).

Tres cuadros de los aquí reproducidos sobresalen por su carácter fuertemente definido en cuanto a la esencia de lo que representan; en La labor (figura 2) y en el supuesto retrato de la madre del pintor (figura 18), la raigambre española está a flor de piel. La tercera obra, Las espiritistas, es interesante tanto por el tema como por la captación del ambiente (figura 3). Todo el misterio que rodea a una sesión de espiritismo fue interpretada hábilmente por el pintor. Son sugerentes los rostros de los asistentes y en particular el de la medium; sin embargo, la carga expresiva descansa en las manos llenas de emotividad e iluminadas con un efecto propositivo. Es posible, aun cuando no existen elementos de juicio para afirmarlo, que Téllez haya sido un decidido practicante del ocultismo; así me explico la propiedad con la que trató el tema espiritista.

Sobre el reiterado españolismo y la influencia de Ignacio Zuloaga en Téllez, su cuadro de grandes dimensiones Mujeres de España (figu- 
ra 16) guarda una clara identificación con la obra del maestro vasco. Recuérdese de éste, por ejemplo, su tela Mis primas, y se dirá sin más, que Téllez trabajó su obra bajo el peso que le significaba Zuloaga. Algo semejante es posible repetir respecto al cuadro La gitana (figura 8) tanto por el asunto y su desarrollo al aire libre, no resulta del todo ajeno a una tela de idéntico tema, pintada por Ignacio Zuloaga.

Dos obras de carácter efectista son Bailarina de la India y Danza española (figuras 19 y 29). Las intenciones y la composición de estas telas son semejantes en más de un detalle. Un eje vertical al centro rige la estructura, mientras que un amplio semicírculo marca las ondulantes faldas de las danzantes; el semicírculo en cierta manera encuentra correspondencia con las figuras sedentes que se localizan al fondo de la escena; en el primer caso se trata de hombres que acompañados por la flama de una lámpara, siguen los lúdicos movimientos del cuerpo de la eufórica danzante. No menos frenética baila la mujer española, a la que rodean varias mujeres que lucen sus pintorescas vestimentas; con manifiesta alegría siguen el ritmo de la música con el sonoro palmotco de sus manos. El fondo general de las pinturas es de penumbra, mas la luz desempeña aquí un papel principal, el de iluminar los rostros sonrientes de las bailarinas, el de imprimir un efecto de exotismo en la mujer indú. Comparados estos cuadros con la mayor parte de los que aquí se reproducen, me parece que resultan inferiores. No obstante, al anónimo redactor de El Diario Ilustrado, le causó buena impresión la pintura de la Bailarina de la India, pues escribió lo siguiente: "... dominan las tonalidades amarillas... Al fondo los musulmanes, un tanto sofisticados, así como de los brazos de la baila. rina, prenden luces fosforescentes. Es un atrevido y hermoso estudio de modernismo... Que en este cuadro ha presentado Téllez Toledo". ${ }^{17}$

Como un retratista de singulares méritos fue reconocido Juan Téllez por sus contemporáneos. Entre los retratos que pintố sobresalen los que de sí mismo hizo; de esos autorretratos se reproduce aquí el que le muestra en medio de la imprescindible penumbra, con una calavera sostenida por la mano diestra. El cuadro nos entrega el rostro melancólico de un hombre joven necrófilo, de grandes y profundos ojos y boca sensual que oculta entre los mostachos (figura 1). Posaron para él reiterativamente tanto su padre como su hermana Matilde; el retrato que reproduce la figura 10 llama la atención por el estrafalario

17 Ver nota 9 
atuendo que porta la joven mujer. Por desgracia no conozco los que pintó en Madrid a Luis $G$. Urbina y a Rubén Dario; de este último Ernesto Mejía Sánchez da noticia de la existencia de una carta que el poeta envió al pintor, para manifestarle, posiblemente, su agradecimiento por el retrato. 18

Entre Rubén Darío y Juan Téllez existió un buen vínculo amistoso. Se conocieron en Madrid cuando el poeta era ya embajador de Nicaragua ante la corte de Alfonso XIII; juntos viajaron por España en compañía de Francisca Sánchez. Entre la correspondencia de Darío hay copias de tres cartas enviadas a Téllez, dos fechadas en 1907 y la otra en el año siguiente. En las dos primeras Darío insta al pintor para que viajen juntos a América; Téllez debía acompañarlo a Nicaragua, lo cual no se efectuó. E1 retrato que Juan Téllez pintó a Rubén Dario en Madrid está fechado en 1907. Parece que no es una obra excepcional, pues en una carta al pintor el gran bardo le dice: "El retrato que Ud. me hizo me gusta mucho como a todos los que lo ven apartando el defecto de las manos." Antonio Oliver Belmas, lo describe así:

Este retrato tenía un defecto a los ojos del modelo: una mano gruesa, que en realidad no está acabada, que no pertenecia a las manos reales del autor de "Cantos de vida y esperanza", manos en verdad finas, delgadas, delicadas. Manos de marqués, como decía el propio poeta. Pero en lo demás es un retrato cabal, el poeta aparece con una boina de estudiantes del barrio latino, con barba y bigote, y entre las manos sostiene un libro. La mirada, el gesto, están captados con evidente finura. ${ }^{19}$

El retrato se encuentra actualmente en el Seminario Archivo Rubén Darío de Madrid. En el artículo citado en la nota 14 se reproduce, mas tan pésimamente que no es posible aventurar juicio alguno.

La producción de Juan Téllez que he logrado estudiar es la que

$18 \mathrm{Si}$ es que existe el archivo de la correspondencia de Roberto Montenegro, allí debe encontrarse la carta de Danio a Téllez; a decir de Mejia Sánchez: "Montenegro ha conservado una carta autógrafa de Dario al pintor mexicano Juan Téllez, que a su vez hizo otro retrato al poeta". Véase: "Rubén Darío y los Pin. tores Mexicanos", por Etnesto Mejía Sánchez, en Boletin Bibliográfico de la S.H. y C.P. Año XIII, número 376, páginas 8.9, México, octubre de 1967.

19 Antonio Oliver Belmas, Última vez con Rubén Dario, Madrid, 1978, p. 245. Consúltese también del mismo autor: Este otro Rubén Dario, Barcelona, 1960 De ambos libros provienen las noticias ofrecidas aquí. Mi agtadecimiento al doctor Ernesto Mejía Sánchez por su imprescindible ayuda. 
realizó en España; lo que aquí pintó, si es que lo hizo, me es desconocido. En la exposición de 1908 presentó, según su comentarista, un paisaje sobre El zócalo de Veracruz, mas el grabado que reproduce el cuadro no permite formular ningún juicio sobre el mismo. ¿Aparte de la obra citada trabajó alguna más, sobæe tema mexicano, antes de salir para Nueva York? Por hoy nada se puede responder. ${ }^{20}$

Queda pendiente de consideración en este sucinto estudio de la obra de Juan Téllez, su actividad como grabador. Fuera de las escuetas noticias aquí presentadas, nada he logrado investigar sobre su labor, sin duda interesante, de grabador al aguafuerte. Ojalá algún día se den a conocer sus láminas; es lo único que por hoy, puedo agregar.

Antes de concluir este trabajo deseo manifestar mi agradecimiento al señor Arturo Navarro, por las facilidades que me concedió para conocer, en su mayor parte, las pinturas de Juan Téllez. Gracias le doy también, por su gentileza en proporcionarme las fotografias de los cuadros que pasaron por su galería.

20 En la citada exposición se mostró un cuadro de título sugerente por lo menos: Una pesadilla. 